\title{
Um workshop - Um plano de composição para agir e pensar a partir do "meio"
}

\author{
Paula Caspão
}

1.

Entre 22 e 26 de Outubro de 2012, teve lugar o workshop "Mergulhar num processo", facilitado por André Lepecki e Vera Mantero. Organizado pela Faculdade de Letras da Universidade de Lisboa e pelo Centro de Estudos de Teatro, com o apoio dos Artistas Unidos. 0 workshop decorreu no espaço Estrela 60, que durante cinco dias se transformou numa paisagem provisória de partilha de práticas e saberes vindos de lugares, suportes e tempos heterogéneos.

A proposta de um workshopé um tecido frágil que não existe propriamente antes de acontecer. Ao longo dos dias, em que decorre, a efectivação das suas texturas e dos seus ritmos é um trabalho de todos os momentos; é um trabalho de todos os que ali vierem co-agir e copensar. Quando se desenrola assim, entre uma atenção ao modo como os materiais de trabalho se activam entre todos e através de cada um - independentemente daquilo que já sabiamos (ou imaginávamos) deles - então algo de facto "acontece".

E esse algo não se deve apenas aos materiais com os quais trabalhámos: textos de indubitável força propostos por Lepecki. ${ }^{1}$, juntamente com materiais trazidos por cada um de nós, solicitados por Mantero: um texto curto ou um fragmento de texto; um som; um objecto; uma imagem; uma acção, comportamento ou tarefa - uma espécie de "arquivo pessoal" para constituir ali uma maneira de estar não só entre todos, mas também entre os materiais que nos constituem, importam e movem. E parece-me importante referir antes de mais que a instrução, que recebemos de Mantero para escolher os materiais que levaríamos para o workshop, dizia que tanto podiamos escolher materiais que nos tocam pelo seu conteúdo, por aquilo que significam ou formulam, como escolher aqueles que nos intrigam ou tocam mais pela via sensorial, cinestésica, rítmica, afectiva. No caso dos textos, podiam então ser aqueles que temos vontade de "pôr na boca", escrevia Mantero, independentemente do conteúdo que transportam. Prometendo já actividades de mastigação ou degustação de palavras, indicando já o corpo como um lugar para explorar textos... e os textos como lugares para iniciar movimentos.
2.

Isto está a tomar a forma de um "contar como foi". Paro. Faço aqui um desvio para me situar. Ou melhor, paro para deslocar este "objecto". É que as ideias que aqui transmito não correspondem de maneira fiel ao que exactamente fizeram e disseram Lepecki e Mantero, mas sim à maneira como o que ali teve lugar afectou o meu pensamento. Mal-entendi certamente muita coisa, por isso me parece importante chamar a atenção para a autonomia deste objecto - a sua ineficácia enquanto documento ou relato fidedigno. A verdade é que mais do que deixar uma marca exacta do que "realmente (supostamente) aconteceu", interessa-me abrir aqui um outro espaço, um outro encontro, com outros participantes, convocando outras temporalidades, outros afectos, outros saberes e nãosaberes. Sigo e activo de resto um mapa irregular de notas que se foi desenhando de forma dispersa, distribuído por vários suportes, e acumulando notas nas margens - notas proliferando ao lado das notas do workshop -, dando lugar a alguns arabescos acrobáticos, contiguidades surpreendentes, e por vezes cumplicidades bastante improváveis à medida que os pensamentos, questões, desejos desenvolvidos durante o workshop voltavam com outros timbres, gestos e palavras, através de novas leituras, em outros contextos de trabalho. Outros lugares. Como este, que é outro aqui enquanto escrevo, e que será outro - outra vez - agora que está a ser lido.

E não posso deixar de desejar que cada leitor(a) ocupe estas margens com comentários, palavras soltas, setas, círculos, estrelas, pontos e linhas, dando assim visibilidade e palpabilidade ao facto de a leitura ser uma relação singular, uma colaboração entre vários agentes que produz um texto diferente, uma outra paisagem de sentido, de cada vez que tem lugar.

Este desvio leva-me contudo a uma questão que me parece implícita não só na maneira como Lepecki nos enviou os textos previamente, designando-os de "chão", mas também na maneira como os atravessámos; na maneira como se foram entrelaçando, ressoando com os exercícios propostos por Mantero. Trata-se da questão de "como praticar um texto: que usos pode ter, em que situações?"
Ver no final deste artigo a bibliografia recomendada.

Paula Caspão é investigadora no Centro de Estudos de Teatro da FLUL, bolseira pós-doutoral da FCT. Doutora em Filosofia (Epistemologia / Estética) pela Universidade de Paris Ouest Nanterre, é dramaturgista em artes coreográficas e desenvolve trabalho artístico interdisciplinar. É co-fundadora - com Bojana Bauer, lvana Müller e J-B VeyretLogerias - de "Institut", uma plataforma de práticas críticas e performativas com base em Paris. 
Plano do Jardim Botânico

de Lisboa (Diário do

Governo, II Série, $n^{\circ} 158$ de 6 de Junho de 1962

p. 4798).
Terá a leitura algo de coreográfico?

Tomados no seu conjunto, os textos propostos, da área da filosofia na sua maioria, colocam em contacto zonas temporais e lugares distantes. Pela minha parte, acolhi-os e tratei-os como um tecido cujas partes se podiam tocar entre si antes mesmo de serem lidas: antes de os ler distribuí-os literalmente pelo chão, por cima de mesas, cadeiras, objectos, de modo a formar uma geografia irregular de temas, linhas, interrupções, intersecções, disparidades, (des-)encontros mais ou menos felizes. Optei, pois, deliberadamente por uma leitura sinuosa, concordante com a maneira como entendo um texto: como uma textura que não existe por si, nem como um todo linear, mas que desenha "lugares" com velocidades, tons e vozes variáveis, sempre em relação com um espaço preciso e com um tempo complexo, feito de vários tempos de relação que não fluem necessariamente em linha recta. Como tal, todo e qualquer texto pode ser abordado pelo meio, ou a partir de qualquer zona que não coincida com o princípio, e ser percorrido com movimentos irregulares. Fazendo este percurso, emergem entre zonas distintas de textos distintos uma multiplicidade de alianças, pontes aéreas, simpatias, bem como diferenças e paradoxos relevantes para pensar e repensar. Entre as zonas de potencial diálogo entre os textos, emerge igualmente desde a primeira abordagem-passeio um convite para tentar linhas de consistência não só entre os textos, mas entre as questões que colocam e os nossos métodos de trabalho, as nossas maneiras de viver, de experimentar, de iniciar e/ou inibir movimentos, discursos, encontros.

Como escrevia Lepecki no e-mail que nos enviou com os textos (o "chão", para termos um "plano de imanência" ou de "composição" para "pensarmos em comum"), não se tratava de adoptar uma perspectiva de ansiedade, de ter que ler e "saber" ou "conhecer"; não se tratava de modo algum de captar, numa perspectiva hermenêutica, o sentido que supostamente estaria nos textos à nossa espera de forma prédeterminada pelos seus autores (com as suas supostas intenções). Tratava-se antes de nos propor entrar em relação com os textos adoptando uma posição experimental através da qual fosse possivel "pensar como activar as palavras/imagens/conceitos que cada um deles propõe", partilhar saberes e práticas de várias ordens, repensá-los e (eventualmente) deslocá-los, recolocá-los coreograficamente - tendo em conta a situação presente, com toda a sua complexidade espáciotemporal e relacional. nous? sommes-nous avec toi ? sommes-nous ensemble? que semblons-nous? ferons-nous quelque chose ensemble? que fais-tu de toi? sommes-nous nees ensemble? partirons-nous ensemble? viendras-tu avec nous? irais-je avec vous ? où irais-je avec vous ? que ferais-je avec vous? que faisons-nous ensemble? qui sommes-nous ensemble? que sommes-nous ensemble? qu'êtes-vous ensemble? devonsnous vivre ensemble? devez-vous mourir ensemble? que deviendrons-nous ensemble?

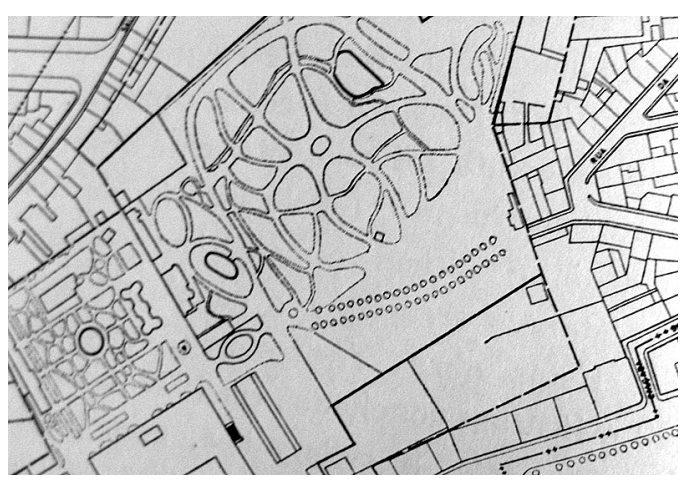

Este "chão", que podemos imaginar em termos geológicos como uma paisagem simultaneamente rochosa e movediça, não deve, pois, ser entendido como um plano no sentido de um objectivo ou resultado a alcançar, um programa ou projecto a realizar, mas antes como um "diagrama", para continuar no pluriverso dos termos deleuzianos (Deleuze 2002: 55, 56). Num sentido muito concreto, o "diagrama" deve ser entendido em termos propriamente geométricos como uma superfície com traços, linhas e manchas, indicando uma topografia onde se intersectam vários ritmos possiveis, várias "possibilidades de facto" (quer dizer, possibilidades que só devêm "facto" quando são utilizadas, quando têm realmente "lugar"). É um "plano de composição", ou "plano de imanência", onde o processo de composição só pode ser entendido através daquilo a que dá efectivamente lugar, naquilo que gera num dado momento. Opondo-se assim ao que seria, segundo Deleuze, um "plano de organização" ou de "desenvolvimento", ou seja, um "plano de transcendência dirigindo tanto as formas como os sujeitos", como algo que não é propriamente dado enquanto tal, mas apenas implícito - enquanto dimensão suplementar prédeterminada - naquilo que gera (Deleuze 2003: 171, 172). Ora, situar-se num "plano de composição" (de "consistência" ou de "imanência"), significa ao contrário situar-se num processo radicalmente local que, prescindindo de toda e qualquer forma pré-definida, se desenrola tendo em linha de conta as relações que se vão efectuando pouco a pouco embarcando em ritmos adequados a cada materialidade implicada. Instalar-se num tal plano implica ademais um "modo de vida", uma "maneira de viver", já que é de facto "imanente", sempre em relação epidérmica com uma situação concreta, muito embora tenha que ser construido, pois, apesar de ser "imanente", não é algo que simplesmente acontece por si. Quer dizer que as condições para que possa acontecer têm que ser criadas. Nesta perspectiva espinozista e deleuziana que nos foi trazida por Lepecki, 


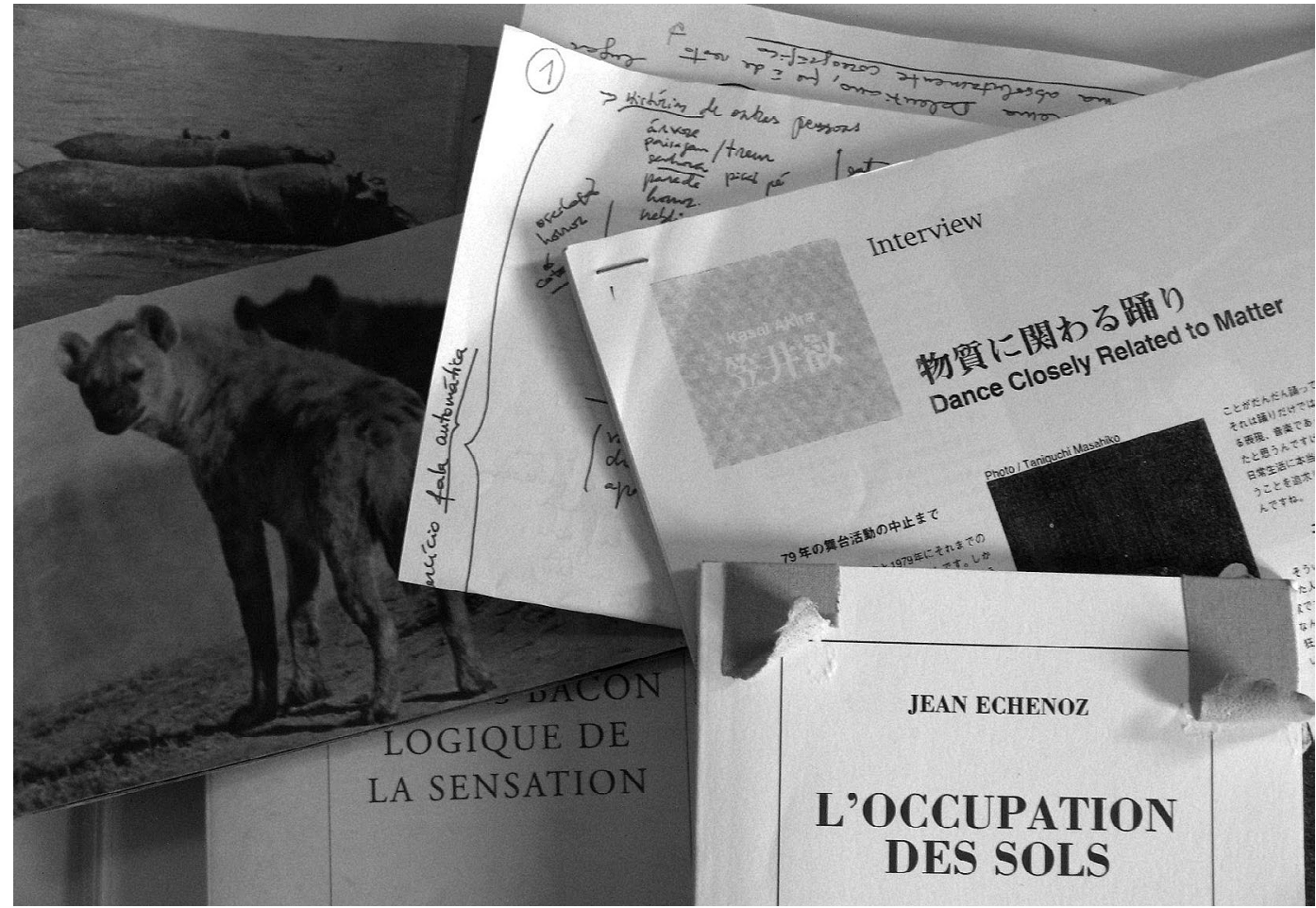

o "comum" ou "chão" formado pelos textos que nos foram enviados não pressupunha então, de maneira nenhuma, que iriamos trabalhar a partir de um "comum" preexistente e pré-determinado. Esse "comum" deve ser entendido como algo que teve que ser construído passo a passo; algo que não se encontrava atrás de nós pré-fabricado mas à nossa frente, como algo incerto, não garantido, e exigindo por isso de todos um envolvimento sensivel.

3.

Faz sentido referir aqui que, no primeiro dia, Mantero propôs um exercício tão interessante quanto inquietante: sentir o chão. Pessoalmente senti-o como um treino a que gostaria de chamar "politico". Em grupos de quatro ou cinco, uma pessoa de cada grupo colava-se ao chão, enquanto os outros iam fazendo pressão sobre o seu corpo, com as mãos e com todas os outros membros e partes que pudessem servir para empurrar o corpo para mais e mais perto do chão. E Mantero ia dizendo que era isso mesmo, entrar pelo chão dentro: "deixar cair a pele contra a carne, a carne contra os ossos, os ossos no chão..." E assim fomos alternando, até toda a gente ter feito a sua experiência daquele chão.

Começa a aparecer claramente a importância do "como fazer" já que entre aquilo que se quer fazer e aquilo que se faz está sempre a questão da adequação do modo de fazer ao que tem que ser feito, questão absolutamente coreográfica e tarefa principal da politica (atender ao chão onde tem lugar), como assinalou Lepecki fazendo referência a Paul Carter (1996), bem como a Gilles Deleuze (para quem um "facto" é aquilo que "tem lugar"). Quer isto dizer que em todo o rigor não deveria haver métodos adquiridos, por muito eficazes que se tenham revelado, pois para cada situação específica, no nosso trabalho artístico como na composição dos nossos modos de viver, há que encontrar o método, a maneira ou as maneiras adequadas ao que tiver que ser feito a cada momento. Pelo que, para além da pertinência de qualquer iniciativa, da acção a efectuar e da ousadia que requer, é importante descobrir qual é a ressonância mais fina entre aquilo que nos move e o modo de expressão/aç̧ão que requer. Aqui se encontram, segundo Lepecki, política e arte. Assim, quando se trate do material linguagem, por exemplo, é importante pensar, seguindo mais uma vez Paul Carter, o modo de colocar as palavras a voar. Quer dizer que é preciso coreografar o modo de lançar as palavras, de as pôr a mexer.

Há por isso todo um trabalho preparatório - mesmo tendo a máxima atenção ao presente --, uma necessidade de tomar tempo para "errar" (não só no sentido de arriscar equivocar-se, como também no sentido de vaguear sem direcção precisa), e os dois capítulos da Lógica da sensação a partir do trabalho de Francis Bacon deram-nos algumas pistas para repensar a questão das metodologias de trabalho que cada um de nós tem vindo a desenvolver. A propósito da necessidade de lutar contra o cliché, contra as imensas camadas de informação, assumpções e representações, que ocupam já a tela ou a mente do pintor antes mesmo de ele começar a pintar (ou, se quisermos, que ocupam cada suporte com o qual começamos a trabalhar), Deleuze refere, relativamente à forma de proceder de Francis Bacon, um conjunto de acções: "fazer marcas ao acaso (traços-linhas); limpar, escovar ou passar com um pano certos espaços ou zonas (manchas-cor); lançar a tinta segundo ângulos e velocidades diversas" (Deleuze 2002: 93). Acções que me puseram a pensar o que significaria, concretamente, transpô-las para outras áreas de actividade que não a pintura, no sentido de dar lugar àquilo a que Lepecki chamou, numa conferência de 2009, o "não saber" como "método rigoroso" ("'not knowing' not as a condition to be overcome (...) but as a rigorous method ") (2011: 193). Versando sobre as políticas e as economias da prática da dramaturgia experimental em dança contemporânea, o texto da conferência sublinha o sugestivo facto de tanto a teoria como a dramaturgia se 


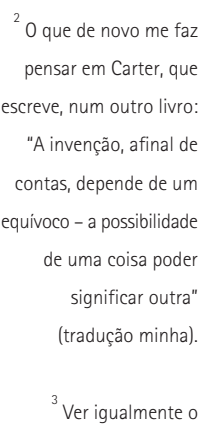
capitulo 11: "La peinture, avant de peindre" (2002: encontrarem marcadas por uma ansiedade comum, que é a ansiedade ligada à questão de "saber ou não saber"; a ansiedade ligada à questão sobre quem é (suposto) saber, isto é, a quem pertence um trabalho e as ideias nele contidas. Formulando a necessidade de sair desta lógica de poder autoral e de investir noutros métodos de relacionamento - entre coreógrafos, dramaturgos, artistas de várias áreas, materiais diversos que participam na consecução de uma peça -, Lepecki propõe o "não saber" como um "método rigoroso" e evoca a possibilidade de usar os textos e a escrita erradamente ("erroneously") ${ }^{2}$. A questão que nos deixa é uma questão deveras exigente: como trabalhar a partir de um "não saber"? Como é que podemos desenvolver uma prática de errância sem ir dar ao chamado "não importa o quê"? Um dos exemplos que Lepecki refere é bastante tentador, e leva-nos a pensar que seria desejável arranjar maneiras de sabotar tudo aquilo que julgamos já saber ou que está já tão estabelecido que nos aparece como natural. Sendo que isto implica todo um trabalho de escavação, de escovagem, de raspagem - de artificialização do "natural", apetece dizer - para fazer surgir essas coisas que já lá estão assumidas como dadas e que por isso já não temos em linha de conta. Fica então a questão: como introduzir (contrabandear?) áreas de não saber, ou de hesitação, no que já sabemos ou julgamos saber? A maneira como Deleuze descreve o trabalho de "deformação" do cliché efectuado por Bacon parece-me adequada a este momento.

Por exemplo, uma boca: pode ser prolongada, pode fazerse que vá de um extremo ao outro da cabeça. Por exemplo, a cabeça: esfrega-se-Ihe uma parte com uma escova, um vasculho, uma esponja ou um pano. Bacon chama a isto um diagrama: é como se de súbito se introduzisse um Sara, uma zona de Sara, na cabeça; é como se nela se esticasse uma pele de rinoceronte vista ao microscópio; é como se se separassem duas partes da cabeça pondo um oceano a meio; é como se se mudasse de unidade de medida e se substituissem as unidades figurativas por unidades micrométricas ou, ao contrário, cósmicas. (Deleuze 2002: 93, 94) ${ }^{3}$.

Tal é o trabalho, prossegue Deleuze, para que seja possivel o surgimento de um outro mundo. Ora, para encontrar a maneira adequada ao que se quer fazer é preciso ouvir a matéria, não só a matéria orgânica, mas também a matéria inorgânica, e a sua capacidade de agenciamento, de afectar e ser afectada. Precisemos, contudo, que ouvir a matéria de que são feitas as coisas não significa de todo voltar a um materialismo determinista, mas tão só ter em conta a maneira como coisas humanas e não humanas co-agem. Na verdade, o próprio corpo humano é composto por diversos outros corpos-coisa ("it-bodies") incluindo bactérias, vírus, metais, como referiu recentemente numa entrevista Jane Bennett (2010). Tratase pois de reconhecer à matéria inorgânica a sua complexidade, a forma como se move e se conecta; a forma como nos conecta e nos move, para o bem e para o mal, ou nenhum dos dois. Necessitamos, assim parece, de uma política da matéria: uma política que tenha em conta a maneira como as diferentes matérias, os objectos e/ou dispositivos se relacionam uns com os outros; e que modos de subjectivação ou dessubjectivação produzem $(2010)^{4}$. Ao mesmo tempo, integrar a matéria não humana na política implica uma mudança na maneira de conceber a actividade política, na medida em que exige uma atenção suplementar não só às forças humanas (intencionais) mas também às forças impessoais que se encontram em jogo a cada momento, à sua capacidade de afectar e ser afectadas; à sua capacidade de produzir diferenças; de fazer, literalmente, a diferença em determinadas situações. Bem entendido, um tal entendimento da política alargando a noção de agenciamento e de afecto à coisa não humana pode nomeadamente conduzir, espera-se, a políticas públicas mais sustentáveis. Ao mesmo tempo, esta mudança de entendimento implicaria reconhecer a que ponto ter em conta a "vivacidade" da matéria não humana é indispensável a uma qualquer "efectividade política", já que esta requer sempre a escolha não só da acção adequada a uma situação, mas também a escolha do estilo dessa mesma acção e do momento certo para agir. Estas escolhas, por sua vez, requerem uma atenção especial à vivacidade que caracteriza as coisas que nos habituámos a considerar como inertes, mas cuja capacidade de produzir informação e de sociabilizar é actualmente inegável, nomeadamente do ponto de vista dos novos materialismos e das teorias do afecto e que em teoria crítica e nas ciências sociais e humanas têm, recentemente, sido referidas à viragem de atenção, na medida em que nelas se percebe o dinamismo inerente à matéria tanto a corpórea e/ou orgânica como a inanimada, reconhecendo a sua capacidade de sociabilizar e de produzir informação (Clough / Halley 2007). Teriamos assim, quem sabe, uma prometedora política, mais virada para a maneira como humanos e não humanos se afectam para as suas maneiras de se aglomerar de determinada maneira em certos lugares ou de co-produzir certas espécies de lugar - uma política mais atenta aos aspectos coreográficos, geográficos (e mesmo geológicos) das relações humanas e não humanas (Kruse / Ellsworth 2002) ${ }^{5}$.

Neste sentido chamou Lepecki a nossa atenção para o uso de "coisas, objectos, tralha em vários trabalhos de dança experimental e performance artrecentes" - como 

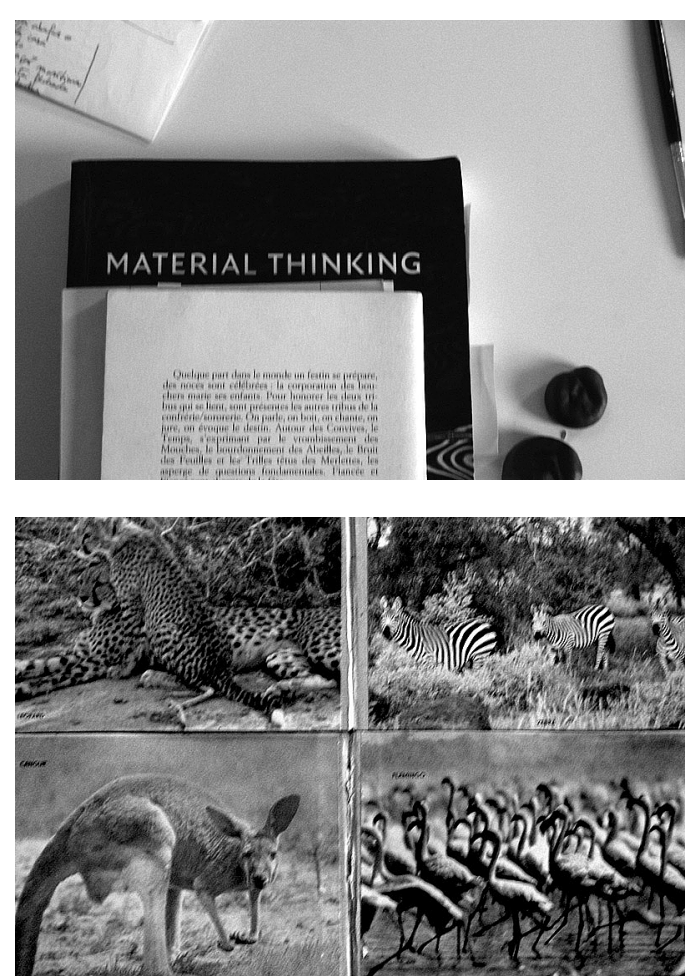

Solo...? (2008) de Aitana Cordero, ou Este corpo que me ocupa (2008) de João Fiadeiro (Lepecki 2012) ${ }^{6}$ - que nos últimos anos têm vindo a integrar esta noção de agenciamento não humano, trabalhando com a performatividade dos coisas e/ou objectos sem os colocar ao serviço do sujeito ou, ao contrário, apresentá-los como coisas-dispositivos que comandam todos os nossos gestos e disposições ${ }^{7}$. Estes trabalhos abrem assim literalmente lugar para outros tipos de relacionamento, para uma contiguidade, uma co-existência entre sujeitos e coisas que deslocam as noções de sujeito e objecto para afirmar "uma ligação profunda entre performatividade e coisidade". (Lepecki 2012).

Na realidade, é caso para dizer que não é o corpo humano que dança, mas a matéria (Kasai 1996): a matéria que constitui os corpos humanos (orgânica e inorgânica), e a matéria que constitui as coisas mais variadas, incluindo a linguagem. Pois também na linguagem não é o dito "espírito" que se move, diz e pensa, mas a própria matéria linguística que dança: a organização do ritmo - as diferenças de velocidade e de intensidade, as variações de tom, de grão e de volume. De facto, a matéria linguistica (ritmica por excelência) relaciona-se de muitíssimo perto com a matéria do corpo humano, sem contudo com ela alguma vez coincidir, como explica Meschonnic (1995: 143). Num outro livro, que já aqui referi, Paul Carter lembra-nos que o termo "discurso" contém de resto um sentido de movimento propriamente físico, designando antes de mais um transporte, uma deslocação de um lugar para outro, de uma situação para outra. É por isso que Carter considera que a prática discursiva não é exclusiva da linguagem, estendendo-se antes a outras matérias, a outros meios e situações, a outras articulações espáciotemporais que não implicam linguagem propriamente dita (2004).

Um outro exercício proposto por Mantero consistiu em trabalhar com os fragmentos de texto que tínhamos

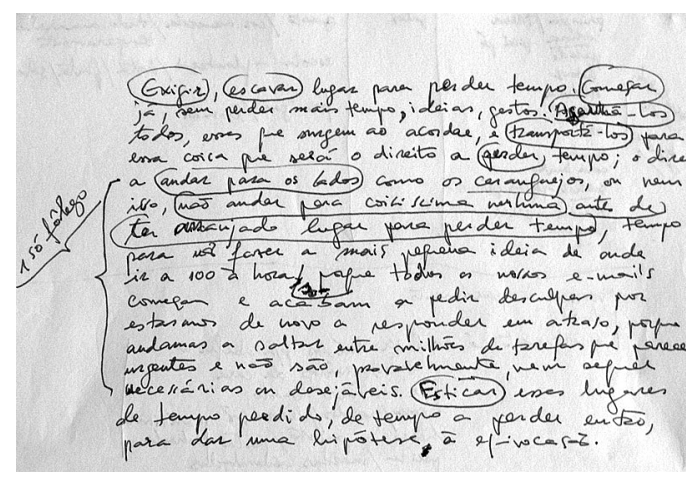

Desdobrável de cartão com animais selvagens. Nota descrevendo uma acção necessária.

levado. A ideia era desprender-nos do significado das frases e do texto como um todo, para nos obrigar a sentir ou a descobrir/inventar as ressonâncias possiveis entre cada palavra e um gesto, uma parte do corpo ou uma sequência de movimentos. Imediatamente apareceu a dificuldade de nos distanciarmos da "atmosfera" já conhecida do texto e das representações ligadas a esse conhecimento, e mesmo à nossa própria experiência sensorial já adquirida do texto. Foi por isso estimulante o esforço para tentar ficar, insistir em cada palavra e com ela tentar engendrar uma relação não propriamente pessoal mas atenta a este novo chão e não sujeita à lógica da representação que nos submerge.

4.

No último dia, após alguns dias de exploração e de transformação do nosso chão, Mantero e Lepecki propuseram que com os materiais trazidos (o nosso "arquivo pessoal" agora já transformado, tendo em conta as experiências que fomos fazendo ao trabalhar com ele), nos juntássemos em grupos de quatro ou cinco para proceder a uma tentativa de desenhar, em cada grupo, um plano de consistência, uma espécie de mapa de possiveis "lugares" onde colocar-se a partir da articulação entre os materiais, as experiências e os pensamentos de cada participante. Mantero deu-nos uma partitura suficientemente larga (passando por linhas tais como: questões fundamentais da existência; questões fundamentais artísticas; questões fundamentais do momento) para organizarmos o material individualmente e passarmos a seguir à negociação para engendrar pontos de ligação ou de tensão, de embate, de ressonância e/ou de sobreposição, de forma a chegar a um plano de consistência - criado não necessariamente a partir de afinidades ou pontos de coincidência, claro está, mas incluindo divergências e discordâncias de várias ordens. No caso do grupo com o qual trabalhei chegámos a uma

\footnotetext{
${ }^{6}$ Sobre as relações entre elementos humanos e não humanos em trabalhos recentes de dança experimental, ver Laermans 2008 e Sabisch
} 2013.

${ }^{7}$ No texto de Agamben ("O que é um dispositivo?"), o autor define um dispositivo como "qualquer coisa que tenha de algum modo a capacidade de capturar, orientar, determinar, interceptar, modelar, controlar e assegurar os gestos, as condutas, as opiniões e os discursos dos seres viventes."
Objectos para produzir um som junto a um livro. 
cartografia exprimindo a necessidade de pesquisar ritmos de vida e formas de organizar o tempo de trabalho em vários lugares do planeta, para tentar perceber que outros ritmos, que outras formas de conceber a experiência do tempo e do trabalho serão possiveis, para além daquelas que já conhecemos (na maioria das vezes distribuidas entre a rapidez e a lentidão, entre a aceleração e a imobilidade). A ideia seria ir compondo um mapa artificial combinando lugares mais ou menos distantes, seguindo a combinatória de ritmos que quereríamos experimentar em contiguidade. Concretamente, cada um de nós viajaria para lugares a determinar (isto implicaria um tempo de preparação, para perceber que geografias poderiam interessar-nos). 0 limite temporal destas estadias de pesquisa corresponderia ao limite da tarefa (perceber/encontrar temporalidades para nós desconhecidas), sendo que a duração restaria assim indefinida; o "plano" poderia, pois, levar muitos anos a acontecer. Os modos de comunicar entre nós seriam também indeterminados, e a descobrir em concordância com os lugares experienciados, as "coisas" e os meios encontrados, e as pesquisas em curso em cada lugar. Não sabemos - nem queremos saber - se seria um trabalho propriamente artístico ou impropriamente social, antropológico, filosófico, político-económico...

Antes de parar de escrever apetece-me perguntar aos leitores em que posição é que leram este texto, e com que ritmo. Se foi de um só fôlego ou se fizeram interrupções, se foi de dia ou de noite, se o chão onde estavam instalados era confortável, se era um chão estável ou um chão que tremia, talvez ao passar por entre as nuvens, poços de ar... Estava quase a sugerir que se fizesse o exercicio de reler este texto em posições inabituais. $\mathrm{Ou}$, em todo o caso, prestando atenção ao que se passa nos vossos corpos durante a leitura. Fica também no ar a possibilidade de se praticar com ele a proposta de Mantero, tentando descobrir ressonâncias impessoais entre palavras soltas e movimentos, de preferência sem cair na ilustração, ou talvez por vezes sim e outras vezes não, só porque é bom apercebermo-nos das diferenças.

\section{Referências bibliográficas (a bibliografia recomendada por Lepecki vem com *)}

*AGAMBEN, Giorgio (2005), "0 que é um dispositivo?", Conferência proferida no Brasil, trad. Nilcéia Valdati http://www.4shared.com/office/IWePMsbE/AGAMBEN_Giorgio__o_que_e_um_d.htm

*ARENDT, Hannah (2007), A condição humana [1958], trad. Roberto Raposo,
Rio de Janeiro e São Paulo, Forense Universitária (capitulo 2. "Acção"). BENNET, (2010a), Vibrant Matters: An interview with Jane Bennett, online: http://philosophyinatimeoferror.wordpress.com/2010/04/22 vibrant-matters-an-interview-with-jane-bennett/ -- (2010b), Vibrant Matters. A Political Ecology of Things, Durham, NC: Duke University Press.

CARTER, Paul (1996), The Lie of the Land, Boston, Faber and Faber.

-- (2004), Material Thinking. The Theory and Practice of Creative Research, Melbourne University Press.

CASPÃO, Paula (2013), Relations on Paper, www.ghost.pt.

CLOUGH, Patricia Ticineto / HALLEY, Jean (2007), The Affective Turn. Theorizing the Social, Duke University Press.

*DELEUZE, Gilles (2002), Francis Bacon. Logique de la sensation [1981] Paris, Seuil.

-_ (2003), Spinoza. Philosophie pratique [1981], Paris, Minuit.

*KASAl, Akira (1996), "Dance Closely Related to Matter" (Interview), Review, No. 2 Summer.

*KLEIST, Heinrich von (1998), "Sobre o teatro de marionetas" [1810], trad. José Filipe Pereira, Edição Acto, Instituto de Arte Dramática.

KRUSE, Jamie / ELLSWORTH, Elizabeth (2002), Geologic City. A Field Guide to the GeoArchitecture of New York City, Smudge Studio.

LAERMANS, Rudi (2008), "'Dance in General' or Choreographing the Public Making Assemblages", Performance Research. On Choreography, 13 (1).

LEPECKI, André (2011), "'We're not Ready for the Dramaturge': Some Notes on Dance Dramaturgy", in Rethinking Dramaturgy: Errancy and Transformation (Eds. M. Bellisco, M.J. Cifuentes, A. Ecija), Murcia, Centro Párraga.

-- (2012), "9 variações sobre coisas e performance", in www.ceart.udesc.br/ppgt/urdimento/2012/Urdimento\%2019/ Artigo9_variacoes_sobre_coisas.pdf

MESCHONNIC, Henri (1995), Politique du rythme. Politique du sujet, Lagrasse, Verdier.

*PERNIOLA, Mario (2005), O sex appeal do Inorgânico [1994], trad. Nilson Moulin, São Paulo, Colecção Atopos (capitulos 1, 2, 3, 21, 22).

*RANCIĖRE, Jacques (1998), "Dix thèses sur la politique", Aux Bords du politique, Paris, Gallimard.

SABISCH, Petra (2013), "Conversation between Petra Sabisch and Paula Caspão", in CASPÃO 2013 